\section{National Health Service}

SIR,-I, like many others, feel that the sands are running out in connexion with the nationalization of the medical profession. At the moment all is apparently quiet on the horizon. 'The Minister of Health is being entertained by certain of the royal medical societies and all is peaceful. But one morning we shall wake up to find the profession in the position of a third-rate Civil Service, and all is lost. The Socialist Medical Society is working quietly but effectively in spreading their propaganda in town and country, and unless we rouse ourselves we shall find ourselves " too late"-as Carlyle remarked, " the two saddest words in the English language." May I suggest, that, as the vast majority of the profession in the British Isles oppose the nationalization of the profession, it is a duty incumbent upon all of us, to the public and to ourselves, to inform the public upon every possible occasion of the position of affairs. Many opportunities occur-to the general practitioner especiallyin the course of casual conversation after purely medical questions are settled. The public are intensely interested in all matters associated with illness and the cure and care of the sick, especially women, and naturally so.

Having been qualified just on fifty years, I can definitely say that I have never personally known a medical man put his comfort or self-interest before that of his patient, and I believe the public have that same point of view. The influence of the medical profession in this country is enormous, and should now be used to further the best interests of both the public and the profession, which are identical.-I am, etc.,

Burwash, E. Sussex.

HOWARD M. STRATFORD.

SIR,-May I request a little space in which to take up one or two points raised by Dr. C. Grantham-Hill and Dr. A. E. Moore (Oct. 25, p. 97), the more so since circumstances have prevented my seeing the earlier letters to which they refer and I may therefore hope to be unprejudiced in comment on theirs ? Although I cannot claim Dr. Grantham-Hill's length of experience in a Government medical service I can claim half that length much more recently-in the R.A.M.C. during the last war, following six years' general practice, which followed nine years' mixed experience of hospital and general work. I have not yet, even in the orderly medical officer system of the Army, or in co-operation with others in practice, found a rota system in which the man on duty was not glad to have his duty taken for him; and more than once found it was becoming customary to ask officers known to be accommodating to "hold on," with the sanction (verbal and easily obtained) of higher authority, for periods of a few minutes to hours or even to a complete exchange of duty. On occasion reciprocal courtesy was asked and received.

I am, if I may say so, entirely at one with Dr. Grantham-Hill's argument and attitude, but I cannot share his fears that any rota system, if introduced, will not prove as flexible. I would suggest that the trivial cases, after trying to get their money's worth, will-also because they are human-revert to waiting till they know their own doctor is available instead of calling in a stranger, that it will not do the rota doctor any harm to find out what is wrong with the borderline cases, and that he will have enough common sense and courtesy to pass on the serious case immediately he knows it belongs to a man who wishes to see such cases for himself, on or off duty.

Nor can I, wrong though I may be, easily visualize even the camarilla of Dr. Moore's nightmare attempting to interfere with reasonable flexibility of a rota system or anything else tending to improve the efficiency of the service. Except for the selfseeking politicians whose colour is not quite clear, all these bogies belong to the party which will, by the patients who are electors, be judged responsible for the Service. Hardly anything could contribute to the downfall of the present Government more certainly than a breakdown of a service they claim as peculiarly theirs-which it is therefore to be presumed they would wish to avoid. And a politician who from a place of power in any other party sought to destroy it by undue interference after it was working well would clearly be courting too much unpopularity to be anything but quixotic. Nor, whether Dr. Moore is right or wrong as to the result of the Government becoming the owner of all private practice in England, can that come about under the present or, one may say, any foreseeable wo future Act. It is, I understand, anticipated in the present Act 3 that everyone will continue private practice among people who $\mathbb{D}$ do not wish to take advantage of the Act ; and it is, I find, also $c$ thought that some practitioners will desire to stay outside it altogether, which it leaves them open to do.

A man who really believes that he surrenders professional $\frac{7}{\sigma}$ independence by joining any service will probably receive the reward of his convictions by finding a competence outside it. I $\overline{\bar{\omega}}$ can well remember as a boy being told by a very senior prac- $\vec{T}$ titioner that his son, then in practice, would of course not touch $\_$ the panel and therefore had no need of the expense of a car. For Government to become the owner of all private practice in $\vec{A}$ England a directly confiscatory Act like that concerning the? railways would be necessary, with, in our case, prohibition of $\overrightarrow{\vec{H}}$ practice outside the Service, with about as much result as any prohibitive legislation there may now be against faith healing or $\partial$ herbalists.-I am, etc.,

Bristol.

C. T. NORRIS.

SIR,-The time is now approaching when we have to make up our minds whether we are prepared to serve in the new Health Service. I understand that when the N.H.I. Act was $\vec{A}$ brought into force a number of those who had been most $\vec{\infty}$ vociferous in opposing the Act were the first to join up, and I을 consider it most important that such a fiasco should not occur $\vec{G}$ again. I therefore suggest that each vote against accepting $\vec{T}$ service should be accompanied by a legal agreement binding the $Z$ voter to pay a substantial sum to the defence fund in the event of his accepting service without the consent of the B.M.A. or a 3 further plebiscite. The amount should be at least one year's emoluments under the new Service or the compensation value of his practice, whichever is the greater, and he should agree to $\vec{\theta}$ pay over $25 \%$ of each panel cheque until the whole sum has been paid.

If such a guarantee were given against the breaking of one's pledge it would make each signatory much safer, and further it would enormously enhance the value of the plebiscite, for in the event of a substantial majority against acceptance it would show that the profession really meant business. I for one do® not intend to bind myself to stop out of the Service unless I can be sure that others will not vote "No" and then later sign up. 윽 This time it is a question not only of the loss of large numbers of patients but also the loss of compensation for our practices. I am, etc.,

Birmingham.

C. H. Heaton.

Association Notices

\section{AREAS OF MID-ESSEX AND SOUTH-EAST ESSEX} DIVISIONS

Notice is hereby given by the Council to all concerned that $N$ the urban district of Burnham-on-Crouch and the rural districts $D$ of Southminster and Bradwell-on-Sea have been transferredㅡㅡ․ from the South-east Essex Division to the Mid-Essex Division.

Charles Hill. Secretary.

\section{Branch and Division Meetings to be Held}

GREENWICH AND DEPTFORD Division.-At Seamen's Hospital, Greenwich, S.E., Wednesday, Nov. 19, 8.30 p.m. Clinical meeting. North OF ENGLAND Branch.-At Royal Victoria Infirmary, Newcastle-upon-Tyne, Thursday, Nov. $20,7.15$ p.m. Clinical Demon- $\frac{\vec{D}}{\mathbb{D}}$ stration in the Dental Hospital by Prof. J. Boyes: Diseases of the Oral Mucosa ; 8.45 p.m., Address by Mr. R. C. L. Batchelor: The Role of Penicillin in the Treatment of Venereal Diseases.

Sunderland Division.-At Sunderland Royal Infirmary, Thursday, Nov. 20, 3.30 p.m. Annual Address by Prof. Sydney Smith: Alcohol and Behaviour. 7.30 p.m. Annual Dinner.

Correction.-In our report of the Annual Panel Conference (Supplement, Nov. 8, p. 106) Dr. F. E. Gould was incorrectly said to be representing Wolverhampton. The city should of course have been Birmingham. 